\title{
Double Retroaortic Left Renal Vein
}

\author{
${ }^{1}$ Shoaib Z Junejo, ${ }^{2}$ Sandeep Singh, ${ }^{3}$ Sandeep Tuli
}

\begin{abstract}
Double left renal vein is a rare venous anomaly. Usually, it remains clinically silent until discovered accidently during an operation or imaging. We present a case of a double retroaortic left renal vein (RLRV). This variation is rare and has been very rarely reported.
\end{abstract}

Keywords: Embryonic renal venous collar, Inferior vena cava, Left subsupracardinal anastomosis, Retroaortic left renal vein, Retroaortic renal veins.

How to cite this article: Junejo SZ, Singh S, Tuli S. Double Retroaortic Left Renal Vein. Int J Recent Surg Med Sci 2017;3(2):117-118.

\section{Source of support: Nil}

Conflict of interest: None

\section{INTRODUCTION}

Double left renal vein is a rare venous anomaly. The incidence of RLRV has been reported from 0.5 to $3.6 \%{ }^{1}$ Usually, it remains clinically silent until discovered accidently during an operation or imaging. We present a case of a double RLRV. This variation is rare and has been very rarely reported.

\section{CASE REPORT}

A 29-year-old woman with past medical history of multiple sclerosis was brought to the emergency department with complaints of right upper quadrant (RUQ) abdominal pain. The only physical finding was abdominal tenderness in the RUQ. Results of the laboratory analysis revealed leukocytosis. Results of her blood metabolic panel and liver function tests were all normal. Abdominal computed tomography (CT) with contrast was performed for further evaluation of her abdominal pain, which showed an incidental finding of double RLRV (Fig. 1).

\footnotetext{
${ }^{1,2}$ Resident, ${ }^{3}$ Attendent

1,2Department of Internal Medicine, Queens Hospital Center Jamaica, New York, USA

${ }^{3}$ Department of Radiology, Queens Hospital Center, Jamaica New York, USA

Corresponding Author: Shoaib Z Junejo, Resident, Department of Internal Medicine, Queens Hospital Center, Jamaica, New York, USA, Phone: +3474224189, e-mail: shoaibzahoor @gmail.com
}

\section{DISCUSSION}

The renal veins connect the kidney to the inferior vena cava, which are usually singular to each kidney and located anterior to the aorta. The incidence of RLRV is 1.7 to $3.4 \%$ of the population. To understand the development of this variation, the embryogenesis of the renal vein system should be considered. By 8 weeks of embryogenesis, circumaortic renal ring is formed. ${ }^{1}$ As development continues, the primitive venous drainage obliterates and normal renal vein is developed. Hoeltl et $\mathrm{al}^{2}$ classified retroaortic renal veins as two main types, according to the obliteration type of embryonic renal venous collar. Type I was developed by the persistence of the left subsupracardinal anastomosis, the intersupracardinal anastomosis, and the left dorsal renal vein. Type II is formed by the anastomosis of the left subsupracardinal and the supracardinal vein. These variations are not so uncommon and should be known by radiologist and surgeon alike as they have major clinical implications in practice and they contribute to the safety of renal and retroperitoneal surgery. ${ }^{3}$

\section{CONCLUSION}

Here, we present a rare case of double RLRV. With the help of anatomic knowledge in renovascular structures and venous variations, the iatrogenic injuries can be prevented during several invasive procedures and thus, avoid significant hemodynamic complications.

\section{CLINICAL SIGNIFICANCE}

Variations in the normal anatomy of the renal vasculature can be life threatening, if not recognized prior to surgical interventions. Vascular anomalies are predisposed to form dilations and can easily be injured during surgical procedures. ${ }^{4}$ Computed tomography is frequently use for imaging kidney and retroperitoneal region. Studies shows that 1.5 to $3.2 \%$ of abdominal CT imaging detects renal vein anomalies. ${ }^{5}$ The RLRVs can be pressed between aorta and the vertebra resulting in increasing pressure in left kidney causing hematuria, referred to as "posterior nutcracker phenomenon." ${ }^{\prime \prime}$ In addition, compression of an RLRV can also result in varicocele formation and ureteropelvic junction obstruction. ${ }^{7}$ Congenital renal vascular variations can cause renal vascular congestion that clinically manifests as hematuria, left flank pain, and pelvic congestion. ${ }^{8,9}$ 


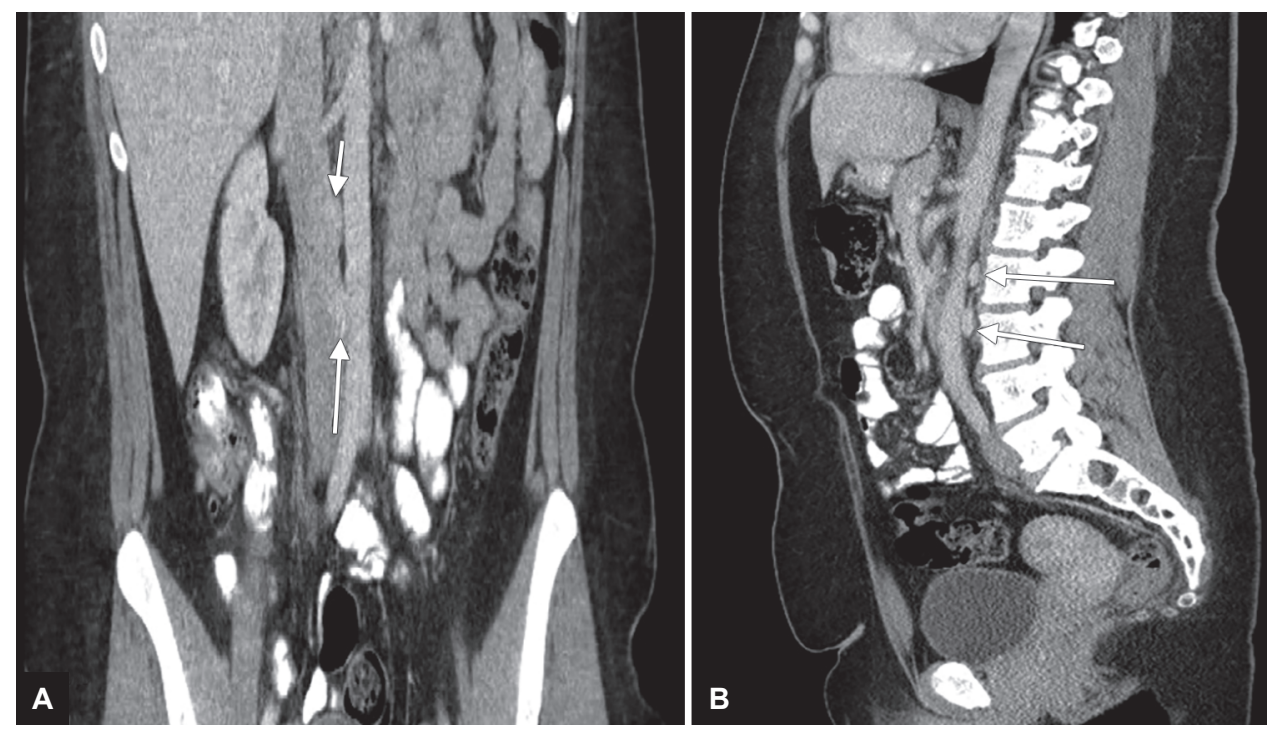

Figs 1A and B: Double retro-aortic left renal vein

\section{REFERENCES}

1. Karaman B,Koplay M,QzturkE, Basekim CC, OgulH,MutluH, Kizilkaya E, Kantarci M. Retroaortic left renal vein: multidetector computed tomography angiography findings and its clinical importance. Acta Radiol 2007 Apr;48(3):355-360.

2. Hoeltl W, Hruby W, Aharinejad S. Renal vein anatomy and its implications for retroperitoneal surgery. J Urol 1990 Jun;143(6):1108-1114.

3. Martinez-Almagro A, Almenar Garcia V, Martinez Sanjuan V, Hernandez Gil de Tejada T, Lorente Montalvo P. Retroaortic left renal vein: a report of six cases. Surg Radiol Anat 1992 Dec;14(4):361-366.

4. Karazincir S, Balci A, Görür S, Sumbas H, Kiper AN. Incidence of the retroaortic left renal vein in patients with varicocele. J Ultrasound Med 2007 May;26(5):601-604.
5. Thomas TV. Surgical implications of retroaortic left renal vein. Arch Surg 1970 Jun;100(6):738-740.

6. Bhattarai C, Poudel PP, Baral P. Congenital anomaly of left renal vein. JNMA J Nepal Med Assoc 2009 Oct-Dec;48(176):328-330.

7. Rudloff U, Holmes RJ, Prem JT, Faust GR, Moldwin R, Siegel D. Mesoaortic compression of the left renal vein (nutcracker syndrome): case reports and review of the literature. Ann Vasc Surg 2006 Jan;20(1):120-129.

8. Cuéllar i Calàbria H, Quiroga Gómez S, Sebastià Cerqueda C, Boyé de la Presa R, Miranda A, Alvarez-Castells A. Nutcracker or left renal vein compression phenomenon: multidetector computed tomography findings and clinical significance. Eur Radiol 2005 Aug;15(8):1745-1751.

9. Arslan H, Etlik O, Ceylan K, Temizoz O, Harman M, Kavan M. Incidence of retro-aortic left renal vein and its relationship with varicocele. Eur Radiol 2005 Aug;15(8):1717-1720. 